\title{
Redes Associativas e de Comunicação Entre as Câmaras de uma Capitania, São Paulo (SÉculo XVIII)
}

Associative and Communicative networks Among the Councils of One Captaincy, São Paulo $\left(18^{\text {th }}\right.$ CENTURY)

Denise Aparecida Soares de Moura* denise.moura@franca.unesp.br

RESUMO: este texto discute a interlocução horizontal que existiu entre as câmaras da capitania de São Paulo no século XVIII. Esta interlocução foi, em grande medida, formal, episódica, ocorrida por meio da troca de ofícios. Discutia questões da administração cotidiana das vilas e contribuiu para criar um sentido de ligação entre estas instituições, a ponto de levá-las,em algumas circunstâncias, a agirem em conjunto na representação de seus interesses junto aos poderes centrais. Este texto apoia-se na matriz teórica que defende a noção de autonomia e autogoverno das câmaras em relação às instituições políticas centrais situadas no reino. Durante o desenvolvimento da pesquisa, contudo, tanto na historiografia quanto na pesquisa empírica foram encontradas evidências de que estas noções incluíam também a relação horizontalizada entre as instituições municipais. Para desenvolver este trabalho foram utilizados ofícios trocados entre as câmaras da capitania de São Paulo e cartas e representações escritas e enviadas por estas instituições para o Conselho Ultramarino.

PALAVRAS-CHAVE: câmara, escrita, comunicação.

ABSTRACT: This text discusses the horizontal dialogue among the Councils of the São Paulo captaincy in the $18^{\text {th }}$ century. This dialogue was overwhelmingly formal, as it went on by the exchange of paperwork, and its subject was about matters of the administrative everyday life of the villages. This exchange of correspondences among the Councils contributed to create a sense of linkage among these institutions, and, because of this, they worked together in some circumstances in defense of their interesting in the face of the central government. This text is supported on a theoretical base that defends the notion of autonomy and self-government of the the Councils. During the development of this research, however, evidences were found both on the historiography and empirical research that these notions had horizontal relations among these municipal institutions. In this work, documents exchanged among the Councils of the São Paulo captaincy, letters, and paperwork written and sent from these institutions to the Overseas Council were used.

KEYWORDS: city council, communication, writing.

Tanto na documentação municipal quanto na correspondência oficial do Conselho Ultramarino constata-se que existiu na colônia uma interlocução horizontal entre as Câmaras Municipais de uma mesma capitania. Esta comunicação foi circunstancial, ocorria pela via escrita e dizia respeito aos problemas do cotidiano administrativo da colônia, como construção e conservação de caminhos, arrecadação de recursos para pagamento dos salários de funcionários régios, medições de rossio, abastecimento, dentre outros assuntos.

Há rastros, nestes mesmos papéis, de que esta comunicação não se restringiu à troca de ofícios, mas envolveu, também, a veiculação informal de "notícias" sobre

\footnotetext{
* Doutora em História Econômica com ênfase em temas brasileiros do século XIX pela Universidade de São Paulo (USP). Profa. de História do Brasil do Departamento de História da Universidade Estadual Paulista, campus de Franca.
} 
determinados assuntos. Em algumas circunstâncias esta interlocução horizontal teve caráter político. Problemas como o envio de representantes para Lisboa, sugestões de como deveriam ser cobrados os tributos que formavam a receita régia ou sobre questões relativas à estrutura burocrático-funcional da capitania, também fizeram parte da comunicação entre os conselhos, porém em escala menor em relação aos problemas da administração cotidiana e imediata.

Esta comunicação de ordem administrativa ou política, formal ou informal, estimulou a adoção de ações em conjunto entre as Câmaras, ou seja, estas instituições formalizaram suas demandas, decisões e relações com os poderes régios na colônia ou no ultramar individualmente, através de cartas ou representações dirigidas, respectivamente, ao rei ou ao Conselho Ultramarino. Contudo, tais escritos foram produzidos simultaneamente ou em datas aproximadas, sugerindo uma ação política associada.

Alguns autores, na historiografia brasileira, de fato, recentemente, vêm anunciando esta atuação cooperativa entre as Câmaras, porém restringindo-a ao âmbito fiscal. Conforme concluem: havia "atuação conjunta entre as câmaras para tomar decisões sobre receitas municipais ou contestar impostos régios" (COSTA, 2012, p. 113-122). Entretanto, ainda são necessárias pesquisas empíricas mais densas sobre os escritos produzidos por estas instituições e que se encontram dispersos nos arquivos municipais.

O tema da existência de uma rede comunicativa entre as câmaras no século XVIII contribui para reforçar a tese do poder de autogoverno destas instituições há muito defendida tanto pela historiografia portuguesa como pela brasileira (MAGALHÃES: COELHO, 1986; FRAGOSO: GOUVÊA: BICALHO, 2000), porém fora da chave analítica predominante e que ressalta a existência de uma comunicação vertical destas instituições com os poderes centrais ou intermediários ${ }^{1}$.

De modo geral, os trabalhos focalizam a comunicação das câmaras com o rei ou com o Conselho Ultramarino. No Brasil, perspectivas pioneiras nesse sentido destacaram "a grande capacidade de comunicação dos poderes da periferia com o centro", e as Câmaras, como parte destes poderes periféricos, teriam se constituído em verdadeiros instrumentos

\footnotetext{
${ }^{1}$ Aplico a definição de Nuno Monteiro para o caso português, ou seja, corpos políticos que se situavam entre o centro e a escala local, ou seja, vice-reis, governadores, ouvidores, corregedores, etc. Cf. Monteiro, op. cit, p. 114.
} 
de mediação na colônia (BICALHO, 1999, p. 481; BICALHO, 2003, p. 352). Posteriormente, esta conclusão foi empiricamente confirmada e ampliada em pesquisas realizadas sobre outras unidades regionais da América portuguesa (JESUS, 2006, p. 21; COMISSOLI, 2006, p. 28; MONTEIRO, 2010, p. 81).

A abordagem do tema da comunicação política dos conselhos no Império português, em perspectiva verticalizada, pode estar associada à constatação feita por texto clássico sobre o assunto de que a comunicação direta com a Coroa era, antes de tudo, um privilégio (RUSSELL-WOOD, 1977, p. 27). Tal constatação se ajustava, portanto, às diretrizes teóricas previstas na leitura da História do Brasil-colônia à luz das estruturas sociais da antiga sociedade portuguesa (GODINHO, p. 55-94; FRAGOSO; GOUVÊA; BICALHO, 2000), que passaram a se dedicar à investigação dos governos locais nos domínios coloniais.

Mas o vigor institucional das câmaras, sua força de opinião e pressão junto às esferas intermediárias e centrais da administração do Império podem ser pensadas à luz da sua própria rede comunicativa, que tanto tinha caráter administrativo como político e contribuía para exercitar seus vínculos, acionados em circunstâncias históricas específicas para uma atuação em conjunto.

Este tipo de atuação em conjunto não escapava à própria gestão documental da época, que organizava em listas, ou juntava em um mesmo tipo de documento, todas as cartas das câmaras escritas para o rei e que continham o mesmo teor. Em uma lista não datada, que pode ter sido organizada pela Câmara da cidade de São Paulo, foram listadas sete representações, com os dizeres logo abaixo: "todas estas câmaras agradecendo a S. A. R. a feliz escolha do actual governador e captam. General pedem unanimemente a sua conservação naquela capitania e para este fim fazem uma enumeração dos benefícios que elle tem procurado aquelles povos" ${ }^{2}$. Seis destas representações foram escritas no mês de outubro de 1804.

Na documentação municipal há, portanto, vários indícios da existência de uma interlocução horizontal entre as Câmaras de uma mesma capitania, ou seja, as Câmaras comunicavam-se entre si, exerciam seu direito peticionário e elaboravam os conteúdos de

\footnotetext{
2 1804, Setembro, 30, São Paulo. Carta dos oficiais das câmaras das vilas de Cunha, Porto Feliz, Itú, Taubaté, Parnaíba, Sorocaba e Moji das Cruzes, ao primeiro regente [D. João] sobre os agradecimentos pela permanência de Antonio José da Franca e Horta no cargo de governador e capitão general da capitania de São Paulo. AHU - São Paulo, cx. 22, doc. 11.
} 
suas representações após se consultarem mutuamente, admitindo, inclusive, a força da representação coletiva, especialmente quando contavam com a assinatura da câmara principal da capitania.

A existência de uma interlocução entre as instâncias municipais na América portuguesa no século XVIII pode dizer respeito, também, às tensões entre a antiga tradição de governo consultivo, das Cortes e Conselhos, para a do período Joanino, caracterizada pela perspectiva de rapidez nas decisões políticas tomadas por um seleto grupo de secretários e agentes (BICALHO, 2010, p. 352-353).

Ou seja, as mudanças na ordem e percepções políticas do Império não enfraqueceram a memória consultiva e participativa dos corpos políticos situados no ultramar. Contrariamente, a comunicação política ganhou força no plano municipal como mecanismo de fortalecimento da comunicação com as autoridades régias, o rei e o secretário do Conselho Ultramarino.

O autogoverno e poder alcançados pelas Câmaras diante dos poderes centrais e intermediários esteve, portanto, também associado à ação cooperativa entre as Câmaras de uma determinada capitania, e, esta, por sua vez, esteve condicionada pelo exercício cotidiano de uma interlocução pela via de troca de ofícios ou mesmo pela via informal.

Este texto, portanto, parte de uma matriz teórica, a que defende a relativa autonomia dos poderes locais constituídos na América portuguesa em relação aos poderes régios. Contudo, na pesquisa de campo, me deparei com situações que permitem problematizar e, em grande medida, documentar a construção da autonomia destes poderes locais não apenas no âmbito da relação com os poderes centrais e intermediários, mas a partir da interlocução das próprias câmaras entre si.

Assim, na primeira parte deste artigo, mostro a existência de uma rede comunicativa entre as câmaras situadas na capitania de São Paulo, baseada na troca de ofícios, que tanto trataram de problemas da administração cotidiana como da sua representação política no Império. Acredito que esta interlocução horizontal contribuiu para alimentar uma cultura política associativa municipal, acionada em circunstâncias posteriores, quando as câmaras demandaram coletivamente ou simultaneamente ao rei ou ao secretário do Conselho Ultramarino, conforme mostrarei na segunda parte deste artigo. 


\section{1-Uma Rede Comunicativa Municipal}

O trabalho de refazer a rede comunicativa municipal na América portuguesa pode se dar por via direta ou indireta, ou seja, por meio do rastreamento de dados pulverizados nos próprios documentos produzidos pelas Câmaras ou nos escritos dos governadores. Para feliz sorte dos pesquisadores, o Arquivo Histórico Municipal de São Paulo possui uma única caixa chamada "Conselho de Vereadores", que guarda um total de 138 ofícios, sendo 130 remetidos por câmaras de vilas litorâneas ou de serra acima para o Senado da Câmara da cidade de São Paulo, e, que a partir de agora chamarei apenas Senado, visando distinguir das outras Câmaras da capitania, que não possuíam este título. Nas atas deste Senado também há indicações de que na ocasião de realização das vereanças eram redigidas "cartas", que estabeleciam a comunicação entre estas instituições ${ }^{3}$.

Os ofícios enviados pelas câmaras da capitania para o Senado estão distribuídos do seguinte modo na caixa acima:

Gráfico 1. Proveniência e quantidade de ofícios enviados pelas Câmaras da capitania para o Senado. Dados recolhidos em Fundo Conselho Municipal de São Paulo, Arquivo Histórico Municipal de São Paulo. 1641-1916, Conselho de Vereadores, cx. 21.

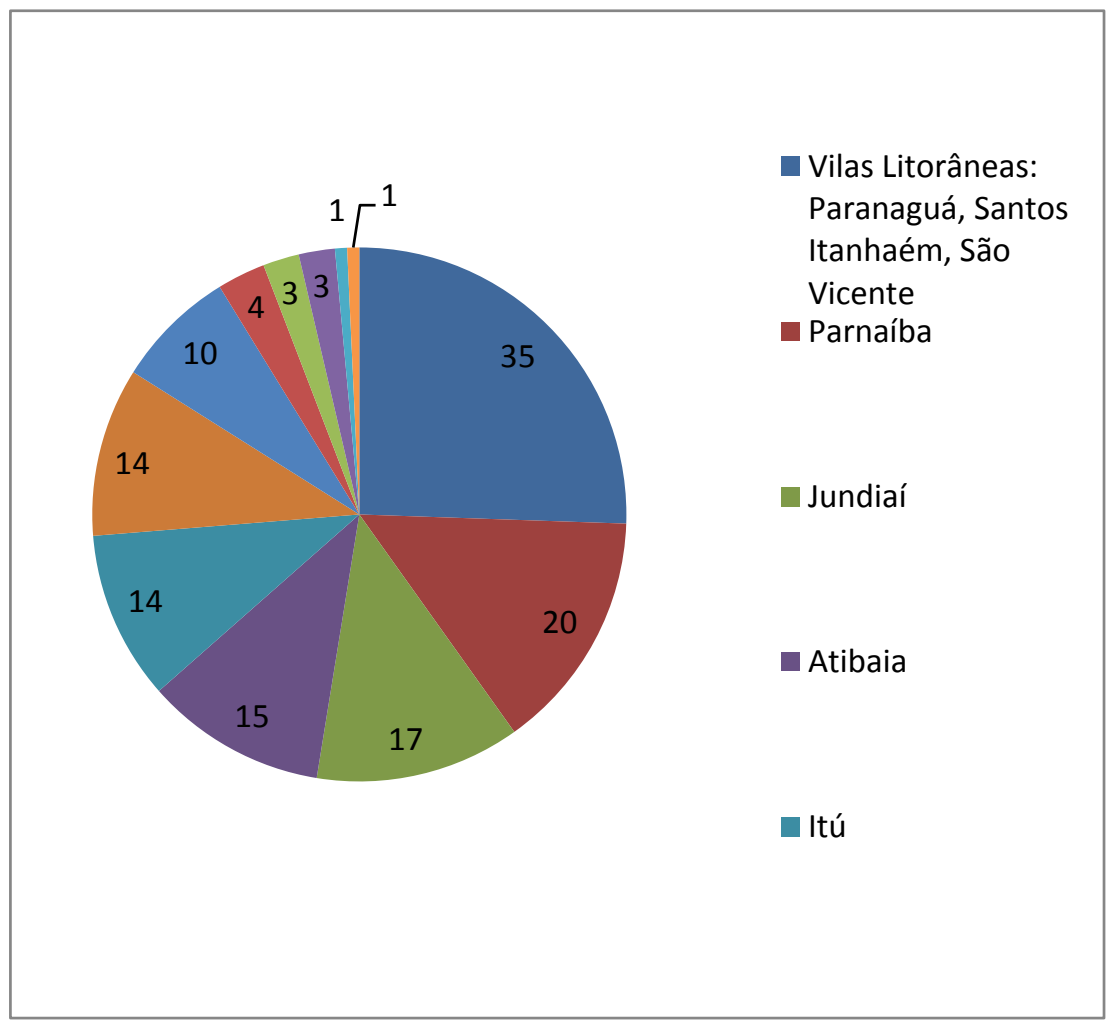

\footnotetext{
3 "e nesta vereança se escreveram cartas à Câmara da vila de São João de Atibaia e ao capitão mor da mesma vila para estes em observância da representação feita ao Ill e Exc. Senhor general mandarem uma pessoa de cada casa para estas virem fazer o aterrado de Santa Anna". Termo de vereança feito aos 2 de setembro de 1775. Atas da Câmara. AHMSP, vol. 16, 1775, p. 427.
} 
Estes dados permitem desenhar um mapa da interlocução municipal na capitania de São Paulo. O polarizador desta comunicação foi a Câmara da cidade de São Paulo, que se intitulava cabeça da capitania, certamente pela sua condição de comarca ${ }^{4}$. Esta não era a câmara mais antiga da capitania, pois sua instalação fora antecedida pelas de São Vicente (1532), Santos (1545) e a de Santo André da Borda do Campo (1553).

Em 1560, o terceiro governador-geral do Brasil, Mem de Sá, dissolveu a vila de Santo André da Borda do Campo, situada no topo da Serra do Mar e, portanto, a meio caminho entre o litoral e o oeste e sul da capitania de São Vicente e transferiu os seus moradores para o planalto de Piratininga, situado entre os rios Tamanduateí e Anhangabaú, onde estava instalado o Colégio dos jesuítas.

Assim, a vila foi refundada sob o nome de Piratininga (QUEIROZ, 1992, p. 58), num processo histórico ainda não bem compreendido pela historiografia, que o explica apenas pelo motivo da busca de maior segurança dos colonos em relação aos ataques dos Tamoios (MONTEIRO, 1994, p. 38).

O critério antiguidade, portanto, não justificava a posição hierárquica superior da Câmara de São Paulo na capitania. O fato de algumas câmaras serem sede de comarca deuIhes precedência política em uma região e a força de tutela sobre Câmaras de vilas. Na ordem de antigo regime português, as estruturas administrativas também eram hierarquizadas (DAMASCENO, 2003, p. 43), o que também explica esta força política de algumas Câmaras.

Certamente, a consolidação e liderança da Câmara de São Paulo no movimento Seiscentista das entradas para os sertões do sul, em direção ao Guairá, fronteira com o atual Paraguai, garantindo de algum modo a presença portuguesa na região, seu status de cidade e Senado, recebido em 1711, e o status similar ao de câmara do Porto, foram fatores que tiveram influência na construção da sua autoimagem de centralidade na região, a ponto de colocar-se numa condição tutelar de outras câmaras, como já foi observado para o caso português (MONTEIRO, 1996, p. 39).

Esta condição da Câmara de São Paulo era, inclusive, reconhecida por outras, pois como escreviam os vereadores da câmara de Paranaguá - que inclusive era a outra comarca

\footnotetext{
${ }^{4}$ Faziam parte da comarca de São Paulo a cidade de mesmo nome, Itú, Santos e Sorocaba.
} 
da capitania - em 1768, entendiam que esta vila, "como mais remota se deve reger pelo estilo desta cidade como capital" (Fundo Conselho Municipal de São Paulo, AHMSP, 18-893), sabendo-se que capital não era uma divisão administrativa da época, mas, segundo o dicionarista Raphael Bluteau, era "o que he como cabeça, principio \& fonte, donde outras cousas se originão, ou donde outras cousas se encerrão".

Neste caso, como a colonização da capitania de São Paulo se deu por sangria das gentes da vila de Piratininga (HOLANDA, 1969), o status de capital, que as outras câmaras atribuíam à cidade de São Paulo, poderia ser derivado deste vínculo de origem das populações das novas vilas, e não meramente da sua condição administrativa de comarca.

Em virtude deste múltiplo status da câmara de São Paulo - comarca, cidade, possuir mesmos direitos que a Câmara do Porto - esta instituição terminou por polarizar a comunicação com as Câmaras da capitania, emitindo ordens, fazendo cobranças de tributos, solicitando esclarecimentos, mas, também, as consultando em relação às questões que fugiam às da gestão cotidiana e, que, posteriormente, seriam conteúdos de seus ofícios enviados para o governador, das cartas redigidas para o rei, ou das representações dirigidas ao secretário do Conselho Ultramarino.

As Câmaras que faziam parte da hinterland da cidade, ou seja, Parnaíba, Atibaia Mogi e Conceição foram as que mais se comunicaram com o Senado, perfazendo um total de 50 ofícios remetidos. Situação esta que pode ser explicada pela proximidade geográfica destas vilas com a cidade, o que as fazia ter um funcionamento articulado. Moradores e cargueiros de alimentos provenientes destas vilas atravessavam rotineiramente o perímetro urbano da cidade de São Paulo (MOURA 2005)

Em seguida, as Câmaras do litoral foram responsáveis por escrever e enviar 35 ofícios para o Senado. As vilas destas Câmaras, exceto Santos, faziam parte da comarca de

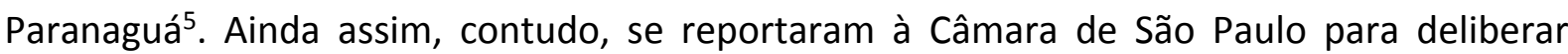
especialmente sobre obrigações fiscais.

Regiões que na segunda metade do século XVIII se projetaram na produção do açúcar para o mercado externo e do Rio da Prata, como Itú e Jundiaí, ou no negócio de animais, como Sorocaba, que inclusive tiveram ligações políticas com o Senado na

\footnotetext{
${ }^{5}$ Formavam a comarca de Paranaguá: Curitiba, Iguape, Laguna, Ilha de Santa Catarina, Cananéia, Rio de São Francisco.
} 
conjuntura da independência (PETRONE, 1968), enviaram, respectivamente, 31 e 10 ofícios. Na comunicação municipal da capitania, portanto, estas Câmaras, que inclusive faziam parte da comarca de São Paulo, ocuparam o terceiro lugar.

Por último, vieram as câmaras do norte da capitania, como Jacareí, Taubaté, Guaratinguetá e Pindamonhangaba, que juntas foram responsáveis por enviar apenas 10 ofícios para o Senado e de fato esta região esteve historicamente mais conectada ao Rio de Janeiro (GARRIDO, 2012).

Boa parte da comunicação das Câmaras das vilas marítimas e de serra acima com o Senado de São Paulo foi sobre o pagamento de tributos relacionados a salários de funcionários régios (ouvidores, corregedores), conservação e construção de pontes e caminhos, os extraordinários (relativos à alguma obra pública de emergência ou donativos régios). Alguns autores da historiografia paulista já demonstraram o quanto as Câmaras da capitania de São Paulo se dirigiam ao governador ou ao rei reclamando de sua baixa arrecadação fiscal, o que a impossibilitava de cumprir muitos compromissos régios (COSTA, 2012, p. 112-122).

Na medida, contudo, em que o Senado era o responsável por fazer a arrecadação destes tributos, certamente devido a sua condição de cabeça de comarca, mas, também, devido a seu status de capital, as Câmaras das várias vilas, inclusive Paranaguá, também uma comarca na capitania, mantiveram correspondência com o Senado de um modo geral reclamando ou mesmo se recusando a pagar os tributos.

Em 1718, a Câmara de Santos respondeu um ofício do Senado que lhe cobrava a remessa de "dinheiros" alegando que, consultado o Provedor da Fazenda este concluiu, com mais "sojeitos inteligentes" que seria injusto enviar estes dinheiros (Fundo Conselho Municipal de São Paulo, AHMSP. 1641-1916, Conselho de Vereadores, cx. 21, s.n).

Especialmente as Câmaras situadas na hinterland da cidade de São Paulo, por fazerem uso mais direto do seu perímetro urbano com seus cargueiros de alimentos que desciam a serra em direção à vila marítima de Santos, tendiam a ser mais cobradas pelo Senado em relação a tributos que seriam empregados na construção de pontes e preservação dos caminhos. 
Estas Câmaras respondiam, não apenas se recusando a pagar o tal tributo, como usando o exemplo de outras situadas em raio de distância maior e que tiveram a mesma atitude.

A Câmara de Atibaia, em 1770, respondeu ao Senado que seus moradores se recusavam a pagar o tributo referente à fatura de uma ponte na cidade de São Paulo que consideravam ser de responsabilidade do mesmo Senado. Segundo seu ofício, "todo este povo uniformemente impugnam ao tal tributo" e fariam do mesmo modo como já haviam feito as vilas de MogyGuassu e Jundiai, "que nos anos passados repudiarão" tais pagamentos, mesmo tendo maiores reditos do que eles. (Fundo Conselho Municipal de São Paulo, AHMSP. 1641-1916, Conselho de Vereadores, cx. 21, 3-12-929).

Evocar o exemplo do que ocorria ou fazia outro conselho parece ter sido uma constante entre estas instituições. A Câmara de Santos, por exemplo, em certa ocasião, representou ao rei contra sua ausência de privilégios, rendimentos e isenções, enquanto outras Câmaras, que consideram possuir rendimentos e posições geográficas menos estratégias, como a da cidade de São Paulo, situada serra acima e distante do mar, o possuíam ${ }^{6}$.

A condição geográfica da cidade de São Paulo, situada na porta de entrada do litoral e, portanto, passagem obrigatória para quem viesse do interior da capitania, fez com que o Senado considerasse que o ônus da gestão da cidade, no que dizia respeito a sua infraestrutura deveria ser assumido também por outras vilas. O Caminho do Mar e a passagem do Cubatão, próximo à vila de Santos, também terminaram por fomentar o estabelecimento de uma rede comunicativa entre o Senado e estas vilas, para deliberarem sobre a divisão dos custos de construção e reparo destas vias.

Através da troca de ofícios para discutir e decidir sobre estas questões, as Câmaras das vilas estabeleciam redes de comunicação e exercitavam uma cultura política de caráter contestatório às imposições da câmara de São Paulo. A câmara de Jundiaí, sobre a questão da reparação dos caminhos da cidade de São Paulo disse que o faria somente até a sua divisa

\footnotetext{
${ }^{6}$ 1768, junho, 25, vila de Santos. CARTA dos oficiais da câmara da vila de Santos ao rei [D. José I] reclamando pelo fato de já não terem os privilégios que tinham antigamente, de receberem certos rendimentos ou serem isentos de certos pagamentos, embora oficiais de outras câmaras ainda os tivessem. AHU-São Paulo, cx. 5, doc. 21 e 22. MOURA, D A S. cd Avulsos 1, P5, P3, 467-505, pág. 1117.
} 
com a cidade, porque o restante cabia ao próprio Senado (Fundo Conselho Municipal de São Paulo, AHMSP. 1641-1916, Conselho de Vereadores, cx. 21, 1796, 10-6-930).

A Câmara de Sorocaba se recusou por completo a arcar com os custos da fatura da ponte do rio Pinheiros, alegando não ter dinheiro e já estar comprometida com "o funeral do monarca e com a ponte da própria vila" (Fundo Conselho Municipal de São Paulo, AHMSP. 1641-1916, Conselho de Vereadores, cx. 21, 1787, 19-05-930)

Algumas Câmaras chegaram a pedir ao Senado documentos comprobatórios do que outras câmaras haviam pago para o conserto de caminhos e pontes, para então deliberarem sobre a quantia que consideravam justo arcar. Assim o fez a Câmara de Parnaíba, solicitando ao Senado que enviasse "a conta" do que cada outra Câmara havia pago para a construção de uma determinada ponte, pois alegavam: "para conforme a determinação de vocês aceitamos ou fazemos nossas súplicas ao corregedor da comarca" (Fundo Conselho Municipal de São Paulo, AHMSP. 1641-1916, Conselho de Vereadores, cx. 21, 1733, 2-10930).

A Câmara de Atibaia, em relação ao rateio entre as Câmaras da capitania para a conservação do caminho de Santos, respondeu ao Senado que "o combinado com outras câmaras não servia para eles" (Fundo Conselho Municipal de São Paulo, AHMSP. 1641-1916, Conselho de Vereadores, cx. 21, 1793, 25-5-930) e antes já havia recusado estabelecer uma finta sobre os moradores, conforme solicitação do Senado, para construção sobre a ponte do rio Tietê porque entendiam que este rio fazia parte da cidade de São Paulo (Fundo Conselho Municipal de São Paulo, AHMSP. 1641-1916, Conselho de Vereadores, cx. 21, 1770, 25-11-929).

Ou seja, as Câmaras das vilas da capitania observavam as determinações impostas e as ações umas das outras antes de atenderem as solicitações, decisões e cobranças do Senado, como pode ser observado com frequência nos papéis produzidos por estas instituições. Quando a Câmara de Guaratinguetá escreveu para o Senado sobre a convocação do povo para elaborarem uma representação "para Lisboa", alegou que o fazia como já havia sido feito pela Câmara de Taubaté (Fundo Conselho Municipal de São Paulo, AHMSP. 1641-1916, Conselho de Vereadores, cx. 21, 1772, 20-12-929). 
A natureza inquisidora e altiva da interlocução das Câmaras das vilas com o Senado, certamente funcionou como um exercício em escala menor do mesmo padrão de comunicação que manteve com os poderes intermediários e régios. Em grande medida, um dos principais problemas do cotidiano municipal, como o das rendas, foi um dos argumentos que mais garantiram o ritmo de continuidade desta interlocução horizontal.

Apesar das inúmeras dificuldades metodológicas enfrentadas pelos pesquisadores, pode-se concluir que os rendimentos das Câmaras, obtidos através dos contratos de abastecimento, licença para exercício de ofícios, abertura de vendas, condenações (coimas), uso dos bens móveis, como casas, ao contrário do que defendem alguns autores (COSTA, 2012, p. 112-113) foram baixos e insuficientes (SOUSA, 2003, p. 143) em relação aos seus gastos com festas e gestão da infraestrutura urbana, como construção e conservação de estradas e pontes (MOURA, 2005; SOUZA, 2007, p. 530).

Por outro lado, conforme já concluíram alguns autores, “as rendas camarárias [...] não tinham apenas valores e papel econômicos. Havia uma série de fatores políticos e culturais que as permeava, que refletia, definia e uniformiza uma estrutura de poder própria das sociedades absolutistas do Antigo Regime" (SOUSA, 2003, pp. 181-182).

Logo, a insistência do Senado em cobrar pagamento de tributos às Câmaras da capitania, inserindo-as numa rede de comunicação formada pela recepção e obrigação de resposta aos seus ofícios, pode ter sido um pretexto para confirmar seu status de "cabeça da capitania".

Nuno Monteiro fez este tipo de observação para outra esfera da administração pública e para o caso português. Segundo ele, o rendimento das Câmaras municipais era reduzido, mas cobrar-Ihe o pagamento de impostos era "pretexto para a tutela dos magistrados régios sobre as finanças municipais" (MONTEIRO, 1996, p. 21).

Este argumento pode ser aplicado para o caso da comunicabilidade fiscal entre o Senado e as Câmaras, porque não há notícias na documentação municipal de imposição de qualquer tipo de sanção pelo não cumprimento das obrigações fiscais. A correspondência de cobrança dos tributos, contudo, preservava a teia comunicativa municipal na capitania. Esta mesma teia comunicativa que contribuiu para nutrir vínculos associativos entre as Câmaras, fazendo-as tomar ciência do que acontecia umas com as outras, a ponto de usarem seus 
exemplos para endossarem suas decisões e a juntarem forças para a ação cooperativa em circunstâncias históricas específicas.

\section{2- $O$ coro das Câmaras: cartas e ações cooperativas como estratégia política}

Edmundo Zenha chegou a mencionar que a formação de "assembleias de câmaras" foi muito praticada no período colonial. Segundo ele, quando se deparavam com "assuntos graves e de interesse da capitania", as Câmaras organizavam uma espécie de "congressos", nos quais se reuniam os procuradores de cada conselho na vila principal (ZENHA, 1947, p. 128).

Posteriormente, a historiografia, fundamentada em pesquisa empírica, confirmou este tipo de experiência ocorrida na colônia e relacionada a deliberações em torno de uma questão fiscal (COSTA, 2012, p. 118), mas ainda não existe investigação suficiente que dê conta da frequência de experiências como estas.

Esta ação em reunião, contudo, pode ter sido mais comum através da troca de correspondências, o que é plausível, tendo em vista as distâncias a percorrer e a característica de funcionamento do Império português pela via da escrita.

Por outro lado, e levando em consideração os estudos que apontam a persistência da memória deliberativa das Cortes, que embora não convocadas no século XVIII, mas evocadas como "espaço legítimo para a resolução de assuntos do reino" (BICALHO, 2010, p. 363), a troca de ofícios entre as câmaras instaurava um tipo de ambiente consultivo e deliberativo virtual e ritmado pela duração das viagens destes papéis para chegarem aos seus destinos.

As próprias Câmaras da vila da capitania demandavam ao Senado a escrita de representações para o rei em conjunto, acreditando na força de um escrito coletivo. A Câmara de Guaratinguetá, quando se organizava para representar ao rei contra a produção de fumo nas minas, que prejudicava a sua economia, convocou a Câmara de Taubaté para participar da formulação deste escrito e pediu para que o Senado também o "sufragasse", pois era capital (Fundo Conselho Municipal de São Paulo, AHMSP. 1641-1916, Conselho de Vereadores, cx. 21, 1772, 20-19-929).

A ação em "assembleia", ou seja, coletivamente, organizada por meio da interlocução horizontal mediada pela troca de correspondências oficiais não se reduziu ao 
problema fiscal, como já foi concluído (COSTA, 2012), mas esteve também relacionada à escala da representação e atuação política no Império.

Mesmo com a reorganização administrativa promovida por D. João V em 1736, que levou a criação de três secretárias de Estado (Secretaria dos negócios interiores do Reino; Secretária da Marinha e Domínios Ultramarinos e Secretaria dos Negócios Estrangeiros e da Guerra), o Conselho Ultramarino ainda conservou seu status de base de comunicação com os poderes locais situados no ultramar.

Algumas conclusões preliminares de investigação em andamento apontaram para a quase inexistência de temas relativos ao cotidiano da colônia na pauta de correspondências do ultramar com a Coroa. Conforme foi escrito, "poucas vezes assuntos como comércio, abastecimento (custo de vida, produção e comércio de alimentos), gestão da justiça ordinária, preservação da ordem hierárquica e saúde pública [apareceram] nas missivas trocadas pelas conquistas ultramarinas com o príncipe" (FRAGOSO; GOUVÊA, 2009, p. 45). Com isto, segundo os mesmos autores, uma base empírica cada vez mais sólida tendia a confirmar a tese do autogoverno das comunidades coloniais.

A leitura das cartas e representações enviadas pelas Câmaras da capitania de São Paulo confirma este diagnóstico. Contudo, juntamente com a chave interpretativa do autogoverno pode-se explicar esta situação à luz da caracterização oceânica do mundo ibero-americano, conforme fez John Russell-Wood (RUSSELL-WOOD, 2009, p. 23). Segundo ele, o atlântico estabeleceu os ritmos do Império, influenciando, dentre outras questões, a governança e a comunicação.

Questões prementes do cotidiano da colônia não podiam esperar o ritmo lento da viagem de ida de uma carta e retorno de sua resposta, o que influenciou os temas tratados nestas correspondências. Segundo John Russell-Wood, uma viagem de ida e volta Lisboa-Rio de Janeiro- Lisboa, considerando as estadias das embarcações em portos brasileiros, poderia levar até um ano (RUSSELL-WOOD, 1998, p. 56). Para portos da costa da capitania de São Paulo, especialmente o da vila do Porto de Santos, deve-se acrescentar um pouco mais, o que daria mais de um ano. Neste sentido, o autogoverno das câmaras na gestão do cotidiano deve ser também associado aos ritmos da viagem oceânica, tanto quanto ao impulso de autonomia dos colonos. 
Decisões fiscais ou os pedidos de nomeação de funcionários podiam demorar, porque mesmo o seu processo decisório e de execução seria lento e emaranhado à burocracia. Mas o preço da carne, o combate aos atravessadores que ocasionavam a falta de alimentos e a carestia, a construção de vias de mobilidade urbana não podiam esperar ante a premência da satisfação das necessidades vitais dos habitantes da colônia.

Questões políticas ou da representação política predominaram na comunicação da colônia com o ultramar, mas este tipo de comunicação, em certas circunstâncias, não se deu isoladamente, mas em conjunto, certamente visando ampliar o poder de sugestão e pressão das Câmaras.

Duas situações ocorridas na capitania de São Paulo são emblemáticas dessa situação. Uma, mais explícita, envolveu a articulação de algumas câmaras da capitania com a do Rio de Janeiro, com o objetivo de enviar um representante às Cortes em Lisboa, em 1725. Outras, mais sugestivas, disseram respeito à elaboração, em datas simultâneas ou muito próximas, de representações cujo conteúdo versava sobre a política econômica do Império ou sobre a defesa da permanência de uma autoridade régia no exercício de sua função.

As Câmaras escreveram para o Conselho Ultramarino um total de 7.980 correspondências, mas a capitania de São Paulo produziu apenas 124 ao longo do período 1642-1822 (MOURA 2014). Neste sentido, aspectos como estes da comunicação e da ação em conjunto entre as Câmaras merecem ser rastreados no universo total destes papéis.

Do ponto de vista das Câmaras da capitania de São Paulo, pode-se dizer que a Câmara do Rio de Janeiro foi quem puxou um coro de envio de um procurador para as Cortes em Lisboa, em 1725. Um chamado como este pode parecer curioso, tendo em vista que o poder de convocação das Cortes recaía sobre o rei ou sobre um seu representante (regente ou governadores) (MAGALHÃES, 1997, p. 74; CARDIM, 1997, 146).

Segundo Cardim, era o rei que decidia o local, o início e o término desta reunião, determinava, ainda, "o tema ou temas centrais da convocatória", definia a margem de poder que deveria ser atribuída aos procuradores e "as questões que deveriam ser discutidas". Segundo este mesmo autor, entedia-se que "algumas questões deveriam ser resolvidas em Cortes - aclamação de novo rei, juramento do príncipe herdeiro, lançamento de novos tributos, quebra de moeda, etc" (CARDIM, 1997, p. 146). 
As últimas reuniões das Cortes, contudo, ocorreram em 1697-1698 (MONTEIRO, 1996, p. 102), mas isto não impediu a permanência do costume de algumas Câmaras enviarem procuradores a Lisboa (BICALHO, 1999, p. 480), o que pode ser tributado ao fortalecimento do direito ancestral de petição do Império na conjuntura da restauração de 1640 (CARDIM, 1997, p. 150).

Passando à frente de uma jurisdição régia, portanto, a Câmara do Rio de Janeiro puxou um coro na capitania de São Paulo, para que, coletivamente, pudessem enviar um representante às Cortes. Esta iniciativa, que ecoou por toda a capitania de São Paulo, evidencia a força do imaginário das Cortes. Acreditava-se que todas as petições eram lidas pelo rei durante a reunião e que os procuradores recebiam imediatamente a resposta do monarca (CARDIM, 1997, p. 148). A possibilidade de uma representação em Cortes também supria a expectativa dos colonos de um rei acessível, que se mostrava aos seus súditos, representados na pessoa do procurador.

A Câmara do Rio de Janeiro escreveu para o Senado argumentado que as Câmaras de suas capitanias eram "tão próximas", sendo, inclusive, do mesmo bispado e província e "como todas as de Portugal se unem com as câmaras que compreende cada uma província mandando muitas vezes procuradores à Corte e os requerimentos".

Concluindo ainda que: "não é justo que nos sendo tão vizinhas não pratiquemos o mesmo, conservando toda a amizade e boa correspondência que sempre houve". Como os custos da viagem para Lisboa eram altos e os "requerimentos comuns", a Câmara do Rio de Janeiro propôs ao Senado que dividissem as despesas. Assim sugeria que cada Câmara competisse com o valor que tivesse condições: "com a quantia que julgarem servir de ajuda para o ordenado que se há de fazer ao procurador".

Assim, concluía, "é preciso fazer um coro e uma uniforme voz de sorte que unidos esse e este senado possa em nome de ambos e de toda a província o procurador que elegemos" (Fundo Conselho Municipal de São Paulo, AHMSP. 1641-1916, Conselho de Vereadores, cx. 21, 1725, s.n.). Nos termos de vereança das Atas da Câmara de São Paulo não encontrei qualquer informe sobre esta convocação da câmara do Rio de Janeiro. Os Registros Gerais do Senado são lacunares para o intervalo 1767-1779, algo que impede a obtenção de mais detalhes sobre como se deu a deliberação sobre este caso. 
Uma convocação deste teor está diretamente relacionada à cultura política Seiscentista (CARDIM, 1998), mas, para efeito deste artigo, o que interessa é a mobilização que este episódio causou ao promover uma intensa troca de ofícios entre o Senado e a câmaras das vilas para organizar este envio de um procurador para Lisboa, que podem ser percebidos por meio dos documentos avulsos conservados na caixa denominada "Conselho de vereadores".

Esta é uma situação interessante, porque sugere que os oficiais da Câmara deliberaram sobre decisões para além das ocasiões da vereança e o historiador que se dedica ao tema das Câmaras Municipais não deve se restringir às atas, registros gerais e às correspondências do conselho Ultramarino, mas examinar nos arquivos municipais todos os papéis e, mais que isto, desconfiar das denominações que os arquivistas do passado deram a papéis municipais que podem conter dados preciosos e reveladores de outras dimensões destas instituições.

A Câmara de Sorocaba esperou um "dia festivo" para "a exposição do negócio" (de dividir os custos de envio de procurador), pois era quando "costumão ajuntarem-se os moradores [da] vila", para então com os "pareceres de todos" responderem ao Senado. Ao final concordaram e prometeram responder com o que pudessem. (s.n). A Câmara de Itú concordou e informou que este procurador deveria tratar com o rei do problema das bixigas (30-7-930). A Câmara de Guaratinguetá não concordou em contribuir, argumentando que “não podiam dar coisa alguma para esse efeito" (10-10-930).

Embora a história dos Conselhos Municipais na colônia tenha avançado significativamente graças a conceituações e referências teóricas macro-políticas (BOXER, 2002) do Império português e da experiência representativa e legislativa das colônias da América do norte (GREENE, 1994), a historiografia ainda lhe dá tratamento monográfico, não investindo na atuação associativa que existiu entre estes governos locais. As Câmaras são tratadas apenas na relação com as autoridades régias. Mas uma mobilização como esta, encabeçada pela Câmara do Rio de Janeiro, mostra que estas instituições agiram também a partir de uma rede comunicativa tecida entre si.

Este ofício enviado pela Câmara do Rio de Janeiro foi escrito em agosto de 1725. Nas Atas da Câmara de São Paulo, deste ano, não há menção ao recebimento deste documento. Mas em março de 1726 houve um termo de vereança (Atas da Câmara, 1726, 
30 de março) com uma manifestação do vereador João da Cunha de Almeida. Sua fala sugere que havia intenção de instituir a cobrança de $\$ 320$ (não especifica) por cada cabeça de escravo para os gastos dos procuradores da Câmara que pretendiam enviar para a Corte, ou seja, o ofício da Câmara do Rio de Janeiro certamente havia sido recebido pelo Senado, mas não fora pauta de vereança. Por outro lado, os vereadores estavam articulando a captação de recursos para o envio do procurador a Lisboa.

Se houve o envio ou não deste procurador a documentação não mostra, mas este caso, se rastreado, poderia resultar numa interessante pesquisa sobre o papel das Câmaras na preservação do imaginário das Cortes no século XVIII e sua influência na pulsão de autogoverno destas instituições e na preservação do próprio Império.

A atuação em conjunto das câmaras é sugerida, ainda, pela elaboração de representações de idêntica temática, teor e em datas simultâneas ou muito próximas umas das outras. Em 13 de janeiro de 1776, o então governador da capitania de São Paulo, Martins Lopes Lobo de Saldanha, encaminhou ao secretario do Conselho Ultramarino, Martinho de Melo e Castro, "cópias de muitas representações, que (...) fizeram muitas câmaras", nas quais expunha o "modo de se aumentarem os reais rendimentos, não só [na] capitania de São Paulo, mas, também, nas outras"7.

Tais representações, produzidas em 1775, foram de autoria das câmaras de Guaratinguetá (4 de novembro); São Luis de Paraitinga (18 de novembro); Pindamonhangaba (19 de novembro); Taubaté (25 de novembro); Mogy (9 de dezembro); São Paulo (27 de dezembro); Jacareí (30 de dezembro). Nota-se, portanto, que tais documentos foram escritos em datas muito próximas, entre novembro e dezembro.

Em documento da caixa Conselho de Vereadores, há indicações de que a Câmara de Guaratinguetá foi quem puxou o coro destas representações com sugestões para a política econômica da colônia já em 1772 (20-12-929). Indícios de que as câmaras podem ter mantido algum tipo de interlocução antes de elaborarem estas representações, aparecem, por exemplo, na nota do governador de que todas as representações apontavam uma "única

\footnotetext{
7 1775, novembro, 18, vila Nova de São Luis da Paraitinga. OfícıOS (cópia) dos oficiais, respectivamente, das câmaras das vilas de Guaratinguetá, Pindamonhangaba, Taubaté, São Luis do Paraitinga, Jacareí, Mogi das Cruzes e cidade de São Paulo, a Martim Lopes Lobo de Saldanha, governador e capitão-general da capitania de São Paulo, datados entre 4 de novembro de 1775 e 7 de dezembro de 1776, todos do mesmo teor, solicitando que se proíba as plantações de cana-de-açúcar e tabaco nas Minas Gerais, assim como o fabrico de aguardente, na mesma região... AHU-São Paulo, cx 7, doc. 2. In: MOURA, D. A S. cd Avulsos 01; P7; P1; 12-137; pág. 1117.
} 
providência" para alcançar tal objetivo, ou seja, de que Minas, Goiás e Cuiabá fossem proibidas de produzir fumo e aguardente.

Assim, acredito que os conteúdos de suas petições e representações, antes de meramente formulados autarquicamente e submetidos a um parecer dos funcionários metropolitanos na colônia, que os enviava para deliberação real (BICALHO, p. 481, 1999), parecem ter sido objeto de consulta coletiva entre várias Câmaras. A argumentação para defender a proposta de extinção da produção de fumo e aguardente era bastante similar, especialmente entre as câmaras mais próximas como a de São Paulo, Mogy das Cruzes, Taubaté e Jacareí. Todas alegavam que, "por orçamento" que fizeram nas capitanias de Minas, Goiás e Cuiabá sabiam que ali existiam "vinte mil vendas". Todas as representações também apresentaram cálculos de quantidade de produtos que poderiam ser vendidos nestas vendas e o quanto renderiam os direitos de entradas destas mercadorias: 350 arrobas de fumo e 480 mil barris de aguardente, que renderiam setecentos e sessenta e cinco contos de reis. Quanto aos direitos de passagens destes produtos para estas capitanias, renderiam a soma de 160 contos de reis.

Ainda, como igualmente argumentavam estas mesmas representações, os transportes destas mercadorias dependiam de "grande número de animais que vindo do sul podem avultar nos direitos de mais de vinte contos de reis". Para a "conduta e administração dos animais e para a mesma laboração das ditas fabricas", ou seja, do fumo e da aguardente, seriam necessários escravos da Costa da Mina, o que aumentaria o pagamento de direitos nas alfândegas.

As Câmaras podiam redigir as suas representações exatamente na mesma data como fizeram Itapetininga, Guaratinguetá N. Sra. da Piedade de Lorena, que, em 29 de abril de 1805, escreveram em favor da preservação de Bernardo José de Lorena no exercício do cargo de governador da capitania. Estas representações continuam justificativas muito similares para o seu pedido, ou seja, este governador fora responsável por promover a agricultura, comércio e conservar a paz. ${ }^{8}$

\footnotetext{
8 1805, Abril, 29, Itapetininga. CARTA dos oficiais da Câmara de Itapetininga, ao príncipe (D. João) solicitando a conservação de Antonio José da Franca e Horta como governador e capitão general da capitania de São Paulo. AHU-São Paulo, cx. 23, doc. 30, cd Avulsos 3, P27, P2, 246-247; 1805, Abril 29, Vila de Guaratinguetá, idem, AHU-São Paulo, cx. 23, doc. 31; cd Avulsos 3, P27; P2, 248-251; 1805, Abril, 29, Vila de Nossa Senhora da
} 
Quando a Câmara de Ubatuba puxou o coro em defesa da permanência de Antonio Manuel de Melo Castro e Mendonça no cargo de governador da capitania, em dezembro de 1800, das sete cartas escritas para o rei, quatro foram redigidas no mesmo mês (abril) e duas nos meses contíguos (fevereiro e março) (MOURA, 2014, p. 1121-1122).

Não necessariamente, a interlocução entre as câmaras, que estavam por trás da ação em conjunto sugerida pelo intervalo de produção e conteúdo destas cartas e representações, se dava de maneira oficial, ou seja, através da troca de ofícios. Nota-se que havia circulação de "notícias".

Boa parte das cartas em apoio à conservação do governador Antonio Manuel de Melo Castro e Mendonça dizia que tinham "notícia" de que o rei iria "rendê-lo" ou "corria a notícia" de que "já estava nomeado novo general", também "constava" que já havia sido nomeado sucessor. Esta, contudo, é uma esfera da comunicação política muito trabalhosa para ser documentada, pois exige a leitura de volumes maiores de cartas e representações camarárias, pois sempre existiu aquele escrivão mais detalhista em apontar circunstância e agentes responsáveis por fazer correr as "notícias" que puxavam o coro das Câmaras em favor de uma causa comum.

\section{Considerações Finais}

Este texto procurou explorar um dos aspectos menos tratados pela historiografia sobre as Câmaras Municipais na colônia: a interlocução horizontal entre estas instituições. A troca de ofícios entre as Câmaras de uma mesma capitania visando tratar de assuntos relativos à administração cotidiana, como consertos de caminhos e pagamento de tributos estabeleceu uma rede comunicativa entre estas instituições.

Em algumas circunstâncias esta comunicação foi além das questões cotidianas e se desdobrou em ações em conjunto, como a da mobilização das câmaras de São Paulo com a do Rio de Janeiro para dividir os custos de envio de um procurador para Lisboa.

As Câmaras tinham percepção de que a representação em conjunto teria maior poder de sugestão e pressão junto aos poderes centrais e, embora não tenham produzido documentos assinados coletivamente, pois cada instituição deveria representar a população

Piedade de Lorena. Idem, AHU-São Paulo, cx. 23, doc. 32, cd Avulsos 3, P27, P2, 252-255. Cf. MOURA, D A S, p. 1125. 
correspondente ao perímetro de seu rossio e termo, o fizeram em data simultânea ou muito próxima. A autonomia destas instituições, em relação aos poderes centrais, deve ser pensada, portanto, não apenas do ponto de vista da sua comunicação individual com as autoridades régias, mas do poder de comunicação que tinham, antes de tudo, entre si.

\section{FONTES E REFERÊNCIAS}

Fundo Conselho Municipal de São Paulo, Arquivo Histórico Municipal de São Paulo. 1641-1916, Conselho de Vereadores, cx. 21.

BICALHO, Maria Fernanda Baptista. As tramas da política: conselhos, secretários e juntas na administração da monarquia portuguesa e de seus domínios ultramarinos FRAGOSO, João e GOUVÊA, M. F. (Org.) Na trama das redes: política e negócio no império português, séculos XVI-XVIII. Rio de Janeiro: Civilização Brasileira, 2010.

BICALHO, Maria Fernanda Baptista. A cidade e o império: o Rio de Janeiro no século XVIII. Rio de Janeiro: Ed. Civilização Brasileira, 2003.

As fronteiras da negociação: as câmaras municipais na América portuguesa e o poder central. In: Simpósio Nacional de História, 20. 1999, Florianópolis,. Anais .... Florianópolis: ANPUH, , 1999. p. 467-483. Disponível em <http://anpuh.org/anais/wpcontent/uploads/mp/pdf/ANPUH.S20.35.pdf $\geq$. Acesso em 15 jul. 2015.

BOXER, Charles. O Império Marítimo Português: 1415-1825. Trad. Anna Olga de Barros Barreto. São Paulo: Comp. das Letras, 2002.

CARDIM, Pedro. Cortes e cultura política no Portugal do antigo regime. Lisboa, Cosmos, 1998.

CARDIM, Pedro. O quadro constitucional. Os grandes paradigmas de organização política: a Coroa e a representação do Reino. As Cortes. In: MATTOSO, J. História de Portugal - o Antigo Regime (16201807). Portugal: Editorial Estampa, p. 145-150, 1997.

COMISSOLI, Adriano. Os "homens bons" e a câmara de Porto Alegre (1767-1808). 2006. $192 \mathrm{f}$. Dissertação (Mestrado em História) - Universidade Federal Fluminense, Niterói, 2006.

COSTA, B. A. A vereda dos tratos: fiscalidade e poder regional na capitania de São Paulo, 1723-1808. 2012. 517f. Tese (Doutorado em História Econômica) -Faculdade de Filosofia, Letras e Ciências Humanas, Universidade de São Paulo, São Paulo, 2012.

DAMASCENO, Claudia. Funções, hierarquias e privilégios urbanos: as concessões dos títulos de vilas e cidades na capitania de Minas Gerais. Varia História, Belo Horizonte, v. 29, p. 39-51, 2003.

FRAGOSO, JOÃO; GOUVÊA, Maria de Fátima e BICALHO, Maria Fernanda Baptista. Uma leitura do Brasil colonial: bases da materialidade e da governabilidade no Império. Penélope, Rioja, n. 23, p. 67$88,2000$.

FRAGOSO, J. e GOUVÊA, Maria de Fátima. Monarquia pluricontinental e Repúblicas: algumas reflexões sobre a América lusa nos séculos XVI-XVIII. Tempo, Niterói, n. 27, p. 36-50, dez. 2009. 
GARRIDO, Felipe de Moura. Produção, comércio e tensões nas vilas do norte da capitania de São Paulo (1788-1808). 2012, 207f. Dissertação (Mestrado em História Social) - Universidade Júlio de Mesquita Filho, Franca, 2012.

GREENE, Jack P. Negotiated authorities: essays in colonial political and constitutional history. Charlottesville and London: University Press of Virginia, 1994.

GODINHO, Vitorino Magalhães. A estrutura da antiga sociedade portuguesa. Lisboa: Arcádia, 1971.

HOLANDA, Sérgio Buarque de. Movimentos de população no século XVII. Revista do Instituto de Estudos Brasileiros, São Paulo, p. 54-11, 1969.

JESUS, Nauk Maria. Na trama dos conflitos: a administração na fronteira oeste da América portuguesa (1719-1778). 2006. Tese (Doutorado em História. - Universidade Federal Fluminense, Niterói, 2006.

MAGALHÃES, J. R. As Cortes. In: MATTOSO, J. História de Portugal - no alvorecer da modernidade. Portugal: Editorial Estampa, p. 73-78, 1997.

MAGALHÃES, Joaquim Romero e COELHO, Maria Helena da Cruz. O poder concelhio: das origens às cortes constituintes. Notas da História Social. Coimbra: Edição do Centro de Estudos e Formação Autárquica, 1986.

MONTEIRO, Livia Nascimento. Administrando o bem comum: os "Homens bons" e a cámara de São João del Rey, 1730-1760. 2010217 f. Dissertação (Mestrado em História Social) - Universidade Federal do Rio de Janeiro, Rio de Janeiro, 2010.

MONTEIRO, N. G.. Os poderes locais no antigo regime. In: Oliveira, César. História dos municípios e do poder local (Dos finais da Idade Média à União Europeia). Lisboa: Círculo de Leitores, 1996.

MONTEIRO, John. Negros da terra: índios e bandeirantes nas origens de São Paulo. SP, Comp. das Letras. 1994.

MOURA, Denise A S. Nas ondas do oceano: o patrimônio histórico-documental das câmaras do Brasil colônia no acervo do Conselho Ultramarino. São Paulo: Cultura Acadêmica, 2014. Disponível em: <http://www.culturaacademica.com.br/catalogo-detalhe.asp?ctl_id=455 . Acesso em 21 ago. 2015.

Poder local e o funcionamento do comércio vicinal na cidade de São Paulo (1750-1822). Revista de História, São Paulo, v. 24, p. 261-290, 2005.

PETRONE, Maria Thereza Schorer. A lavoura canavieira em São Paulo. Expansão e declínio (17651888). São Paulo: Difusão Européia do Livro, 1968.

QUEIROZ, Suely Robles Reis. São Paulo. Madri: Editorial Mapfre, 1992.

RUSSELL-WOOD, A. J. R. Sulcando os mares: um historiador do Império português enfrenta a "Atlantic History". Revista de História, São Paulo, v. 28, n.1, p. 17-70, 2009.

Um mundo em movimento: os portugueses na África, Ásia e América (1415-1808). Lisboa: Difel, 1998.

. O governo local na América Portuguesa: um estudo de divergência cultural. Revista de História, São Paulo, n. 9, p. 25-79, 1977. 
SOUSA, Avanete Pereira. Poder local, cidade e atividades econômicas (Bahia, século XVIII). 2003. 349f. Tese (Doutorado em História Econômica) - Faculdade de Filosofia, Letras e Ciências Humanas, Universidade de São Paulo, São Paulo, 2003.

SOUZA, George Félix Cabral de. Elite y ejercicio del poder en el Brasil colonial: la Cámara municipal de Recife (1710-1822). 2007, 937f. Tesis Doctoral (Doctorado en Historia) -Universidad de Salamanca, Salamanca, 2007.

ZENHA, Edmundo. O município no Brasil, 1532-1700. São Paulo: Instituto Progresso Editorial, 1948. 